\title{
miR-183 inhibits TGF- $\beta 1$-induced apoptosis by downregulation of PDCD4 expression in human hepatocellular carcinoma cells
}

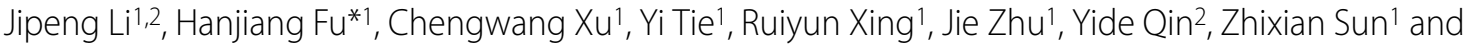 \\ Xiaofei Zheng*1
}

\begin{abstract}
Background: In recent years, some miRNAs have been reported to be connected closely with the development of human hepatocellular carcinoma. In our previous studies, a set of miRNAs were revealed to be dysregulated in HCC tissues. However, the functions of these miRNAs in HCC remain largely undefined.

Methods: The expression profiles of miR-183 were compared between HCC tissues and adjacent normal liver tissues using qRT-PCR method. This method was used to screen the potential target genes of miR-183. A luciferase reporter assay was conducted to confirm target association. Finally, the functional effect of miR-183 in hepatoma cells was examined.
\end{abstract}

Results: Among the 25 HCC samples analyzed, microRNA-183 was significantly up-regulated (twofold to 367-fold) in 17 samples compared with the matching nontumoral liver tissues. Programmed cell death 4 (PDCD4) was identified as the target gene of miR-183. Moreover, PDCD4 is a proapoptotic molecule involved in TGF- $\beta 1$-induced apoptosis in human HCC cells, we found that miR-183 transfectants were resistant to apoptosis induced by TGF- $\beta 1$.

Conclusions: We conclude that miR-183 can inhibit apoptosis in human HCC cells by repressing the PDCD4 expression, and miR-183 may play an important role in HCC development.

\section{Background}

Hepatocellular carcinoma (HCC) is a global health problem, with over 700,000 cases worldwide each year [1]. In the USA alone, it is estimated that there will be over 20,000 new cases of primary liver cancers in 2008, with the majority being $\mathrm{HCC}$ [2]. In china, $\mathrm{HCC}$ is the second highest cancer killer since the 1990s, which alone accounts for $53 \%$ of all liver cancer deaths worldwide [3]. Various molecular alterations occur in preneoplastic nodules and escalate in HCC [4]. Several studies have shown that specific miRNAs are aberrantly expressed in malignant HCC cells or tissues compared to non-malignant hepatocytes or tissue [5-8].

miRNAs have been discovered as naturally occurring non-coding RNAs, controlling gene expression via specific sites at the 3'-UTR of target-mRNAs, causing trans-

*Correspondence: fuhj75@126.com, xfzheng100@126.com

Beijing Institute of Radiation Medicine, 27 Taiping Road, Beijing 100850, People's Republic of China

Full list of author information is available at the end of the article lational repression or degradation $[9,10]$. Recent evidence has shown that miRNA mutations or mis-expression correlate with various human cancers and indicated that miRNAs can function as tumour suppressors and oncogenes. For example, let-7, downregulated in lung cancer, suppresses Ras [11]. miR-15 and miR-16, deleted or downregulated in leukemia [12], suppress BCL2 [13], miR-17-5p and miR-20a control the balance of cell death and proliferation driven by the proto-oncogene c-Myc [14]. Many miRNAs such as miR-21, miR-224, miR-34a, miR-221/222, miR-106a, and miR-203 are upregulated in HCC compared to benign hepatocellular tumors such as adenomas or focal nodular hyperplasia. Many other miRNAs have been noted to be decreased in HCC compared to non-tumoral tissue, such as miR-122a, miR-422b, miR145, and miR-199a [5-8,15].

In this study, we compared the miR-183 expression profile from HCC tumor tissues and adjacent normal liver tissues. We found that miR-183 was up-regulated in HCC 
tumor tissues. Sequence analysis suggested a likely interaction between the 3'-UTR of PDCD4 mRNA and miR183. Therefore, we validated that miR-183 could repress the expression of PDCD4 and analyzed its functions in human HCC cells.

\section{Methods}

\section{Patients and Tumor Characteristics}

HCCs and surrounding control tissue specimens were obtained from 25 patients at General Hospital of PLA (Beijing, P.R. China) after surgical resection with informed consent. The tumor tissues and adjacent normal tissues were frozen in liquid nitrogen after resection. No patient in the current study received chemotherapy or radiation therapy before the surgery. Liver samples were fully clinically characterized (Table 1). This study was performed with the approval of the Medical Ethical Committee of General Hospital of PLA.

\section{Cell Lines and Cultures}

HepG2 and Huh7 cell lines were grown in Dulbecco's modified Eagle medium (DMEM) (GIBCO BRL, Grand Island, NY) containing $10 \%$ fetal bovine serum (FBS) with $100 \mu \mathrm{g} / \mathrm{ml}$ penicillin/streptomycin at $37^{\circ} \mathrm{C}$ with $5 \% \mathrm{CO}_{2}$.

\section{Vector Construction}

Wild-type 3'-untranslated region (3'-UTR) of PDCD4 containing predicted miR-183 target sites were amplified by PCR from HepG2 cell genomic DNA. Primers used: Forward: GAT CTG CAG AAG AAC TCT TGC AGT CTT AGA; Reverse: GAT CAT ATG ATG TCA AGC TTT GGG TCT CTG. Mutant 3'-UTRs were generated by overlap-extension PCR method. Both wild-type and mutant 3'-UTR fragments was subcloned into the pGL3control vector (Promega, Madison, WI) immediately downstream of the stop codon of the luciferase gene, as described before [16]. DNA fragment coding PDCD4 protein was amplified by PCR from HepG2 cell cDNA, and cloned into pCMV-Myc expression vector (Clonetech, Mountain View, CA). Primers used: Forward: GCTG AAT TCG GAT GGA TGT AGA AAA TGA GCA GA; Reverse: CTG CTC GAG TCA GTA GCT CTC TGG TTT AAG A.

\section{miRNAs, siRNAs and transfection}

The miRNAs, siRNAs and miRNA inhibitor were synthesized by GenePharma (Shanghai, China) (miR-183: 5'UAU GGC ACU GGU AGA AUU CAC UG-3'/5'-GUG AAU UCU ACC AGU GCC AAA AU-3'; the si-PDCD4 target sequences were GUG UUG GCA GUA UCC UUA G [17]; miR-183 inhibitor: 5'-AGU GAA UUC UAC CAG UGC CAU A-3'). siRNAs and miRNAs transfections were performed using Lipofectamine 2000 (Invitrogen, Carls- bad, CA, USA). In brief, cells were plated in 6-well plate to $40 \%$ confluence. For each well, $5 \mu \mathrm{l}$ siRNA or miRNA $(20 \mu \mathrm{M})$ were added into $250 \mu \mathrm{l}$ Opti-MEM medium, $3 \mu \mathrm{l}$ of Lipofectamine 2000 into $250 \mu \mathrm{l}$ Opti-MEM medium and then mixed siRNA or miRNA with Lipofectamine 2000. The mixture was added to cells and incubated for 6 $\mathrm{h}$ before replacing the medium. Total RNA and protein were prepared $48 \mathrm{~h}$ after transfection and were used for qRT-PCR or western blot analysis.

\section{RNA extraction and qRT-PCR}

Total RNA was extracted from the cultured cells using Trizol Reagent (Invitrogen) according to the manufacturer's protocol. qRT-PCR was used to confirm the expression levels of mRNAs and miRNAs. For mRNAs detection, reverse transcription was performed according to the protocol of Improm- $\mathrm{II}^{\mathrm{mi}}$ Reverse Transcriptase System (Promega); qPCR was performed as described in the method of SYBR premix Ex Taq (TaKaRa, Dalian, China) with Mx3000p (Stratagen, La Jolla, CA, USA) supplied with analytical software. GAPDH mRNA levels were used for normalization. For miRNAs detection, the qRT-PCR was performed as described before [16]. One primer of miRNAs amplification is miRNA specific, and the other is a universal primer. U6 snRNA levels were used for normalization. The oligonucleotides used as primers was: PDCD4-F 5'-TGG ATT AAC TGT GCC AAC CA-3', PDCD4-R 5'-TCT CAA ATG CCC TTT CAT CC-3'; G3PDH-F 5'-TCA GTG GTG GAC CTG ACC TG-3', G3PDH-R 5'-TGC TGT AGC CAA ATT CGT TG-3'; miR-RT primer 5'-GCG AGC ACA GAA TTA ATA CGA CTC ACT ATA GG(T)18VN-3'; miR-183 5'-TATGGCACTGG TAGAA TTC ACT-3'; universal primer 5'GCG AGC ACA GAA TTA ATA CGA C-3'; U6-F 5'CGC TTC GGC AGC ACA TAT ACT A-3', U6-R 5'CGC TTC ACG AAT TTG CGT GTC A-3'.

\section{Western blot analysis}

Protein extracts were prepared by a modified RIPA buffer with $0.5 \%$ sodium dodecyl sulfate (SDS) in the presence of proteinase inhibitor cocktail (Complete mini, Roche, Indianapolis, IN, USA). Polyacrylamide gel electrophoresis, tank-based transfer to Immobilon Hybond-C membranes (Amersham Biosciences) and immunodetection were performed with standard techniques. Antibodies against PDCD4 (12587-1-AP, ProteinTech, Chicago, USA) and $\beta$-actin antibody (Zhongshan Biotechnology, Beijing, China) were used in western analysis in accordance with the manufacturer's instruction. Signals were visualized with SuperSignal ${ }^{\circ}$ West Pico chemoluminescent substrate (Pierce, Rockford, IL, USA) by exposure to films. 
Table 1: miR-183 and PDCD4 mRNA Expression Profiles in human hepatoma carcinoma tissues

\begin{tabular}{|c|c|c|c|c|c|c|c|c|c|}
\hline $\begin{array}{l}\text { Patient } \\
\text { No. }\end{array}$ & Age & Gender & $\begin{array}{l}\text { Tumer Size } \\
\left(\mathrm{cm}^{*} \mathrm{~cm}^{*} \mathrm{~cm}\right)\end{array}$ & $\begin{array}{c}\text { Edmondson } \\
\text { Grade }\end{array}$ & HBsAg & HCV-Ab & Cirrhosis & $\begin{array}{l}\text { Normalized } \\
\text { miR-183 Amount in } \\
\text { Tumor Tissue } \\
\text { Relative to Adjacent } \\
\text { Normal Tissue 2- }-\Delta \Delta \mathrm{Ct}\end{array}$ & 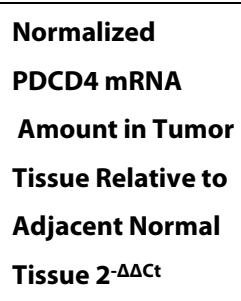 \\
\hline 1 & 35 & $\mathrm{~F}$ & $5 * 4 * 4$ & 3 & Positive & Negative & Yes & 32.90 & 0.37 \\
\hline 2 & 52 & $M$ & $8.5^{*} 7 * 6$ & 2 & Positive & Negative & No & 16.68 & 0.41 \\
\hline 3 & 43 & $M$ & $3.5 * 3 * 2$ & 2 & Positive & Negative & Yes & 6.36 & 0.89 \\
\hline 4 & 41 & $\mathrm{~F}$ & $12 * 10 * 8$ & 3 & Positive & Negative & No & 3.39 & 0.32 \\
\hline 5 & 34 & $M$ & $10 * 7 * 7$ & 3 & Positive & Negative & Yes & 4.96 & 0.41 \\
\hline 6 & 50 & M & $2.5^{*} 2.5^{*} 2$ & 3 & Positive & Negative & No & 23.59 & 0.74 \\
\hline 7 & 33 & M & $10 * 8 * 7$ & 4 & Positive & Negative & Yes & 0.33 & 1.45 \\
\hline 8 & 50 & M & $2.5^{*} 1.8^{*} 1.5$ & 1 & Negative & Negative & No & 0.53 & 0.34 \\
\hline 9 & 52 & M & $10.5 * 8 * 5$ & 3 & Positive & Negative & Yes & 2.08 & 0.4 \\
\hline 10 & 52 & $M$ & $10.5^{*} 8 * 5$ & 3 & Positive & Negative & Yes & 9.06 & 0.92 \\
\hline 11 & 63 & M & $14^{*} 10^{*} 10$ & 2 & Positive & Negative & Yes & 1.29 & 1.25 \\
\hline 12 & 70 & $M$ & $3.5^{*} 3.5^{*} 3$ & 2 & Positive & Negative & Yes & 25.28 & 0.08 \\
\hline 13 & 66 & $\mathrm{~F}$ & $15^{*} 7^{* 5}$ & 3 & Positive & Negative & No & 48.84 & 0.31 \\
\hline 14 & 39 & $M$ & $12 * 11 * 6$ & 3 & Positive & Negative & No & 5.94 & 0.50 \\
\hline 15 & 51 & M & $2.5^{*} 2^{*} 2$ & 2 & Positive & Negative & Yes & 101.83 & 0.35 \\
\hline 16 & 47 & M & $5 * 5 * 4$ & 2 & Positive & Negative & Yes & 0.28 & 0.98 \\
\hline 17 & 37 & M & $16^{*} 4^{*} 8$ & 2 & Positive & Negative & Yes & 367.09 & 0.21 \\
\hline 18 & 52 & M & $8^{*} 7^{*} 4.5$ & 2 & Positive & Negative & No & 0.39 & 1.57 \\
\hline 19 & 64 & $M$ & $8 * 5 * 4$ & 2 & Negative & Positive & No & 0.17 & 6.19 \\
\hline 20 & 50 & $\mathrm{~F}$ & $6 * 5.5 * 2.5$ & 1 & Negative & Negative & No & 130.69 & 0.2 \\
\hline 21 & 52 & M & $7 * 7 * 7$ & 3 & Positive & Negative & Yes & 1.38 & 0.23 \\
\hline 22 & 56 & M & $8 * 6.5 * 5$ & 3 & Positive & Negative & Yes & 0.88 & 0.47 \\
\hline 23 & 48 & M & $2^{*} 2^{*} 1.5$ & 2 & Positive & Negative & No & 48.17 & 0.17 \\
\hline 24 & 59 & M & $8.8 * 8.5 * 8$ & 2 & Negative & Negative & No & 41.93 & 0.26 \\
\hline 25 & 40 & $M$ & $2.5^{*} 2.5^{*} 2$ & 2 & Positive & Negative & Yes & 16.34 & 0.41 \\
\hline
\end{tabular}

HBsAg indicates hepatitis B surface antigen; $\mathrm{HCV}-\mathrm{Ab}$, hepatitis $\mathrm{C}$ virus antibody; $\mathrm{M}$, male; $\mathrm{F}$, female; miRNA, microRNA. Relative quantification was performed by the $2^{-\Delta \Delta C t}$ method with adjacent normal liver tissue sample as a calibrator. Data show the means from three independent analyzes. Every independent analyze was carried out after the RNA extraction step. $\Delta C_{T}$ obtained from real-time PCR was subject to paired t test. The expression levels of miR-183 in tumor tissues were significantly higher than in adjacent normal tissues $(P<0.01, t=-3.07)$, and the expression levels of PDCD4 mRNA in tumor tissues were significantly lower than in adjacent normal tissues $(P<0.01, t=3.69)$

\section{Luciferase Reporter Assay}

HepG2 cells were transfected in 24-well plates using Lipofectamine 2000 transfection reagent. The transfection mixtures contained $100 \mathrm{ng}$ of firefly luciferase reporter plasmid and $5 \mathrm{pmol}$ of miR-183 or $20 \mathrm{pmol}$ of miR-183 inhibitor. pRL-TK (Promega) was also transfected as a normalization control. Cells were collected 48 $\mathrm{h}$ after transfection, and luciferase activity was measured using a dual-luciferase reporter assay system (Promega).

\section{Cell apoptosis}

Huh7 Cells were transfected with miRNAs or siRNAs. TGF- $\beta 1$ (Sigma, st. Louis, MO, USA) was added $24 \mathrm{~h}$ after transfection. $48 \mathrm{~h}$ after incubated, the cells were 
fixed, stained with DAPI and analyzed for morphological characteristics associated with apoptosis. Annexin-V assays were performed using Annexin V-FITC kits purchased from KeyGEN (Nanjing, china) according to manufacturer's protocols. The data are expressed as the percentage of apoptotic cells.

\section{Statistical Analysis of Data}

Unless stressed, all results are expressed as means \pm SD. Differences were assessed by two tailed Student $t$ test using Excel software. $\mathrm{P}<0.05$ was considered to be statistically significant. Paired student's t-test was performed to determine the difference of miRNA's expression levels observed between non-cancerous and cancer tissues.

\section{Results}

miR-183 Is Upregulated in Human HCC

Expressions of miR-183 were examined further in an independent series of primary HCC tumors and adjacent nontumoral livers (The clinical parameter of the HCC patients was shown in Table 1) by using Real-time PCR method. The results shown that miR-183 was significantly up-regulated ( 2 to 300 fold) in $68 \%$ of tumors (17 of 25 patients) compared to the matching adjacent nontumoral liver tissues (Table 1). These results suggest that up-regulation of miR-183 may be involved in most of human HCC development.

\section{miR-183 represses the expression of PDCD4}

To identify the functions of miR-183 in HCC cells, we analyzed putative target genes by using the TargetScan http://www.targetscan.org bioinformatics tools [18]. miR-183 maybe play the role of oncogene, considering it is up-regulated in HCC. For this reason, three tumor suppressor gene, such as death-associated protein (DAP), programmed cell death 4 (PDCD4) and programmed cell death 6 (PDCD6) were selected for further validation. To identify the genuine targets, synthetic miR-183 and negative control RNA were transfected into hepatoma Huh7 cells. qRT-PCR was used to detect the expression levels of those putative target genes. The results of qRT-PCR showed that PDCD4 was down-regulated in Huh7 cells transfected with miR-183, whereas the expression levels of other two genes had no significant change (Fig. 1A).

Western blot analysis also showed that miR-183 markedly reduced protein expression levels of PDCD4 compared with negative control RNA and mock transfected cells (Fig. 1B). All these results reveal that PDCD4 is regulated by miR-183.

To determine the clinical significance of miR-183 target genes, we examined PDCD4 mRNA levels in 25 pairs of matched HCC specimens by qRT-PCR. As expected in Table 1, lower levels of PDCD4 were detected in 17 of 25 tumor tissues as compared with the non-tumor counter- parts. Furthermore, PDCD4 mRNA levels were inversely correlated with miR-183 expression (Fig. 1C), suggesting that the decreased PDCD4 expression might result from a high expression of miR-183 in HCC. However, we also observed that miR-183 up-regulation in \#3, 6, 10, 14 and down-regulation in \#8, 16 could not account for the expression levels of PDCD4. These data suggest that miR183 might play a critical role on PDCD4 regulation in over a half but not all of the HCC patients. These might also represent the complexity of PDCD4 regulation especially in HCC. We speculate that other factors (either protein or RNA) might antagonize or interferer the effect of miR-183 on PDCD4, which needs further investigations.

Interaction of miR-183 with the 3'-UTR of the PDCD4 mRNA Using bioinformatic analysis, we found that the putative miR-183 binding site of PDCD4 3'-UTR was conserved across various species (Fig. 2A). To determine whether PDCD4 was direct targets of miR-183, the human PDCD4 wild-type-3'-UTR containing the miR-183 binding site was cloned into a modified pGL-3 control vector. In parallel, we constructed another reporter vector containing the mutated PDCD4 3'-UTR sequence. These luciferase reporter vectors were cotransfected into HepG2 cells with negative control RNA or miR-183 respectively. The results of luciferase assays revealed that miR-183 could act on wild type PDCD4 3'-UTR, and led to a significant decrease of luciferase activity as compared to control RNA (Fig. 2B). When the putative miR-183 binding site was mutated, there was no significant decrease in relative luciferase activity compared with control RNA (Fig. 2B). The corresponding results were observed when the expression of miR-183 was repressed by antisense RNA (Fig. 2C). These data suggest miR-183 may repress the expression of PDCD4 at posttranscriptional level by targeting its 3'-UTRs. In other words, PDCD4 is a direct target gene of miR-183.

\section{miR-183 inhibits TGF- $\beta 1$-induced apoptosis in Huh7 cells}

PDCD4 is down-regulated in human HCC tissues compared to corresponding non-tumoral liver tissues. Furthermore, PDCD4 is involved in TGF- $\beta 1$ induced apoptotic signaling pathways in the HCC cell line Huh7 [19]. To investigate the function of miR-183 in HCC cells, we transfected Huh7 cells with negative control RNA, PDCD4 siRNA and miR-183 respectively, TGF- $\beta 1$ was added $24 \mathrm{~h}$ after transfection, and cells were further incubated for $24 \mathrm{~h}$. qRT-PCR and western blot results showed that miR-183 and siRNA against PDCD4 led to in a significant decrease of endogenous PDCD4 mRNA and protein levels compared to mock or negative control transfection in Huh7 cells (Fig. 3A, C). At the same time, we found that there were no significant changes in miR- 


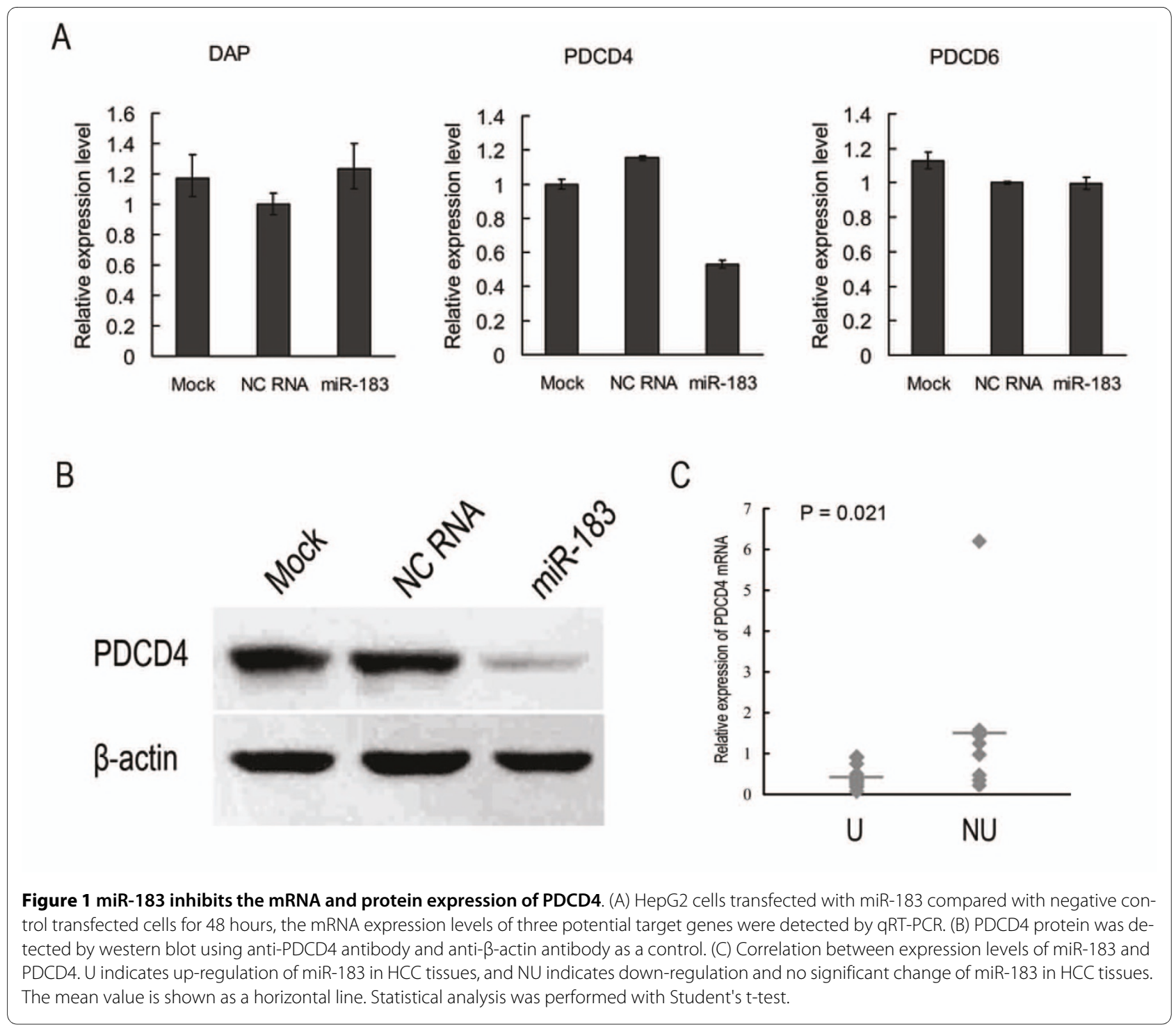

183 expression levels between control cells and Huh7 cells treated with TGF- $\beta 1$ (Fig. 3B).

PDCD4 is a proapoptotic molecule involved in TGF$\beta 1$-induced apoptosis in human HCC cells [19], and miR183 can inhibit TGF- $\beta 1$ induced PDCD4 expression in Huh7 cells (Fig. 3A, C). Therefore, we wondered whether miR-183 could influence apoptosis of Huh7 cells. To eliminate the off-target effect of miR-183 on apoptosis, we used siRNA to down-regulate PDCD4 gene expression. Both of DAPI staining of cells (Fig. 4A) and Annexin-V assays (Fig. 4B) showed that the number of apoptotic cells induced by TGF- $\beta 1$ treatment was reduced in the miR-183 and si-PDCD4 transfectants as compared to the mock and negative control cells. To finalize the function of miR-183-targeting these genes in apoptosis regulation, rescue experiments were carried out. Utilizing pCMV-Myc expression vector, PDCD4 construct without wild 3'-UTR was generated. As shown in Fig. 4C, the inhibition effect of miR-183 on apoptosis was rescued when PDCD4 expression vector was cotransfected. These results indicated that miR-183 was resistant to TGF- $\beta 1$-induced apoptosis of Huh7 cells.

\section{Discussion}

In the current study, we show that miR-183 expression is up-regulated in human HCC compared with matching adjacent nontumoral tissue. We also show that PDCD4 is negatively regulated by miR-183 at the posttranscriptional level, via a specific target site within the 3'-UTR. Moreover, we demonstrated that miR-183 was resistant to TGF- $\beta 1$-induced apoptosis of Huh7 cells, via repression of PDCD4 expression. These results support an essential role of miR-183 in HCC development.

miR-183 is one member of miR-182-183 miRNA cluster located in the 7q31-34 locus [20]. This miRNA cluster including three miRNAs, i.e., miR-96, miR-182 and miR- 
A
H.Sapiens
UUUGUAAGUGCCAUGUUUAUUAUCUAAU
M.Musculus
UUUCUAAGUGCCAUGUUUAGGACCUGAU
R.Norvegicus
UUUCUAAGUGCCAUGUUUAUGACCUAAU
C.Familiaris
UUUGUAAGUGCCAUGUUUAUGACCUAAU
P.Troglodytes
UUUGUAAGUGCCAUGUUUAUUAUCUAAU
M.Mulatta
UUUGUAAGUGCCAUGUUUAUGACCUAAU
O.Cuniculus
UUUGUAAGUGCCAUGUUUAUGAUCUAAU

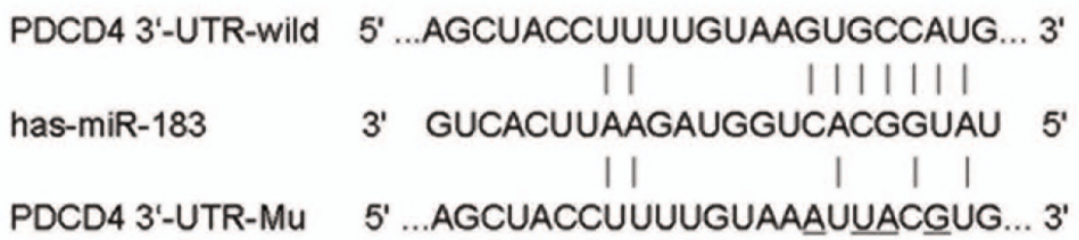

B

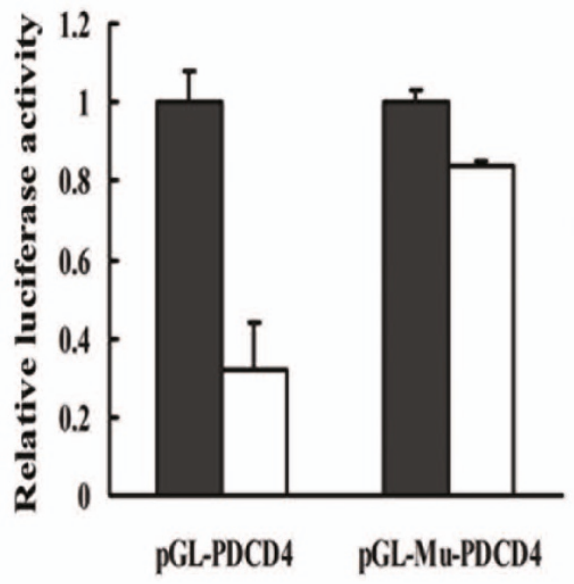

C

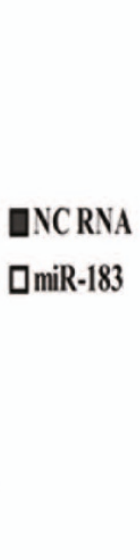

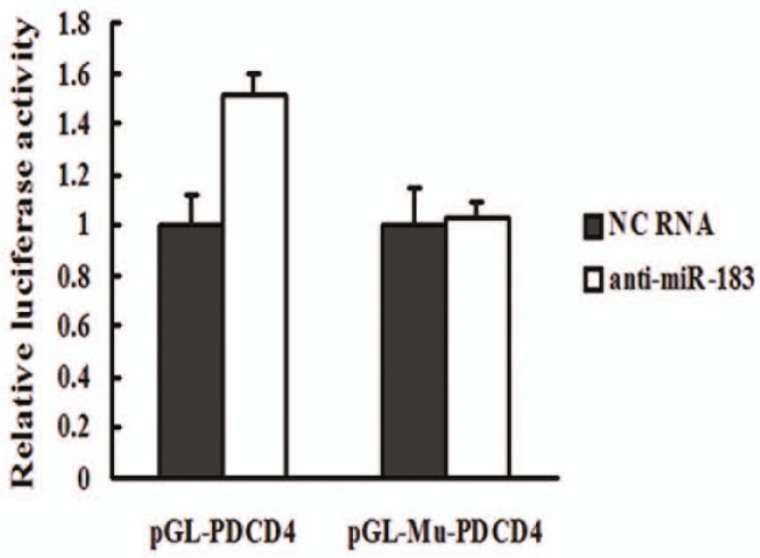

Figure 2 miR-183 can act on the 3'-UTR of PDCD4 directly. (A) The target site of miR-183 in PDCD4 3'UTR is conserved (shown in red) in many species. The PDCD4 3'-UTR mutant is identical to the wild-type, except that it has four point substitutions (red) disrupting pairing to miR-183 seed. (B) and (C) Luciferase assays indicated that miR-183 downregulated the expression of PDCD4 by targeting putative target site. NC RNA, miR-183, and miR183 inhibitor were cotransfected with a modified pGL-3 control vector containing wild-type PDCD4 3'-UTR or mutant, respectively.

183. These miRNAs share highly homologous 5'-seed sequences. Motoyama et al. have found an overexpression of miR-183 in human colorectal cancer and Lin et al. have reported that the miR-183-96-182 cluster was frequently amplified in melanoma [21,22]. Here, we found that miR183 was resistant to TGF- $\beta 1$-induced apoptosis in Huh7 cells, via repression of PDCD4 expression. Thus, it is likely that miR-183 acts as an oncogene in a variety of tumor types. However, miR-183 was identified as a potential metastasis-inhibitor in lung cancer cells [23]. These data suggest that the effect of miR-183 as an oncogene is cell type dependent.

The programmed cell death 4 (PDCD4) was originally identified as a tumor-related gene in humans and mapped to chromosome10q24 $[19,24]$. PDCD4 protein is known to bind eukaryotic initiation factor 4A (eIF4A), inhibit translation initiation $[25,26]$. Moreover, PDCD4 has been found to inhibit AP-1-mediated trans-activation and to 
A

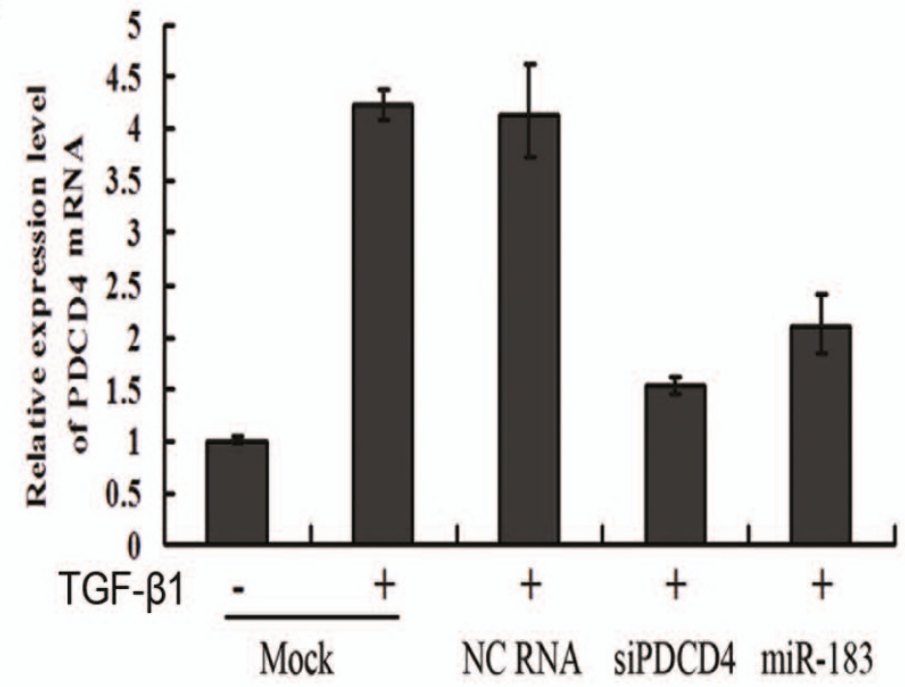

B

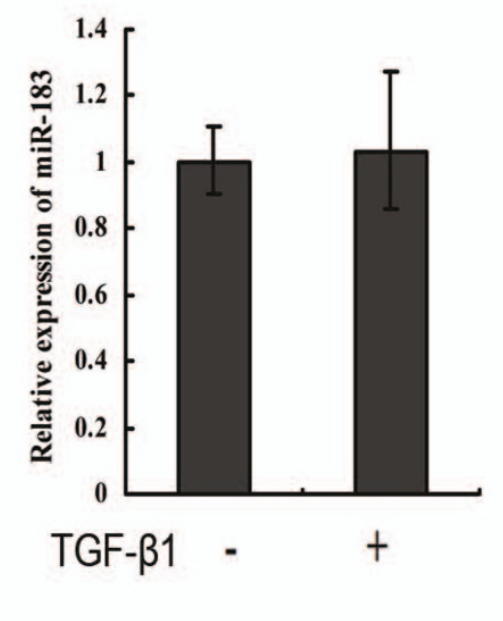

C

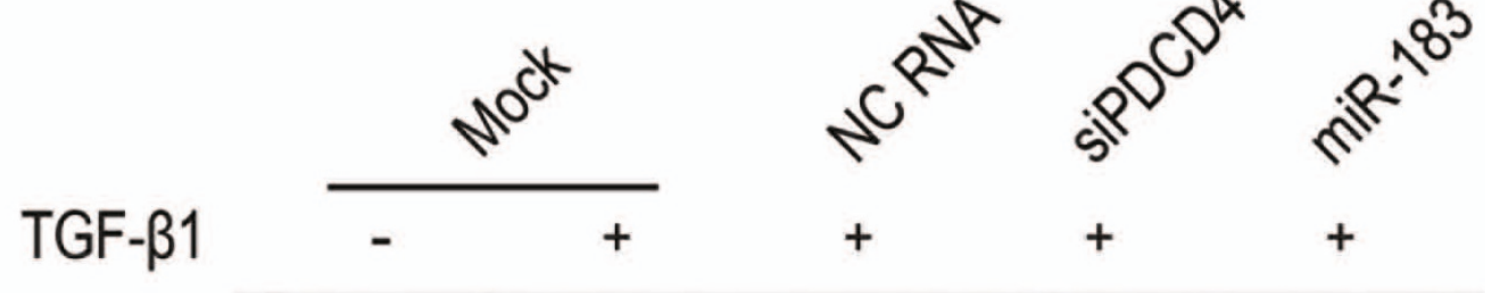

PDCD4

$\beta$-actin

Figure 3 miR-183 inhibits TGF- $\beta$ 1-induced PDCD4 expression in Huh7 cells. Cells were transfected with NC RNA, siPDCD4, or miR-183 respectively, after 24 hours, TGF- $\beta 1(5 \mathrm{ng} / \mathrm{mL})$ was added. Cells were harvested 24 hours later, and were subsequently processed for qRT-PCR (A) and Western blot (C) analysis by hybridization with antibodies against PDCD4 and $\beta$-actin. At the same time, the effect of TGF- $\beta 1$ on miR-183 was examined (B). Huh7 cells were treated with TGF- $\beta 1$ ( $5 \mathrm{ng} / \mathrm{mL}$ ) for $48 \mathrm{~h}$, then harvested and processed for qRT-PCR analysis.

induce expression of the cyclin-dependent kinase inhibitor $\mathrm{p} 21$. As a result, loss of PDCD4 confers growth advantages to the cells by several means and thereby facilitates the development of cancer. PDCD4 expression is downregulated or lost in several tumor types [27]. However, relatively little is known about mechanisms regulating PDCD4 expression in cancer cells. Initial studies have suggested that PDCD4 is regulated by topoisomeraseinhibitors, COX-2-inhibitors, Myb and Akt [28]. In a recent study, PDCD4 has been reported as a functional 


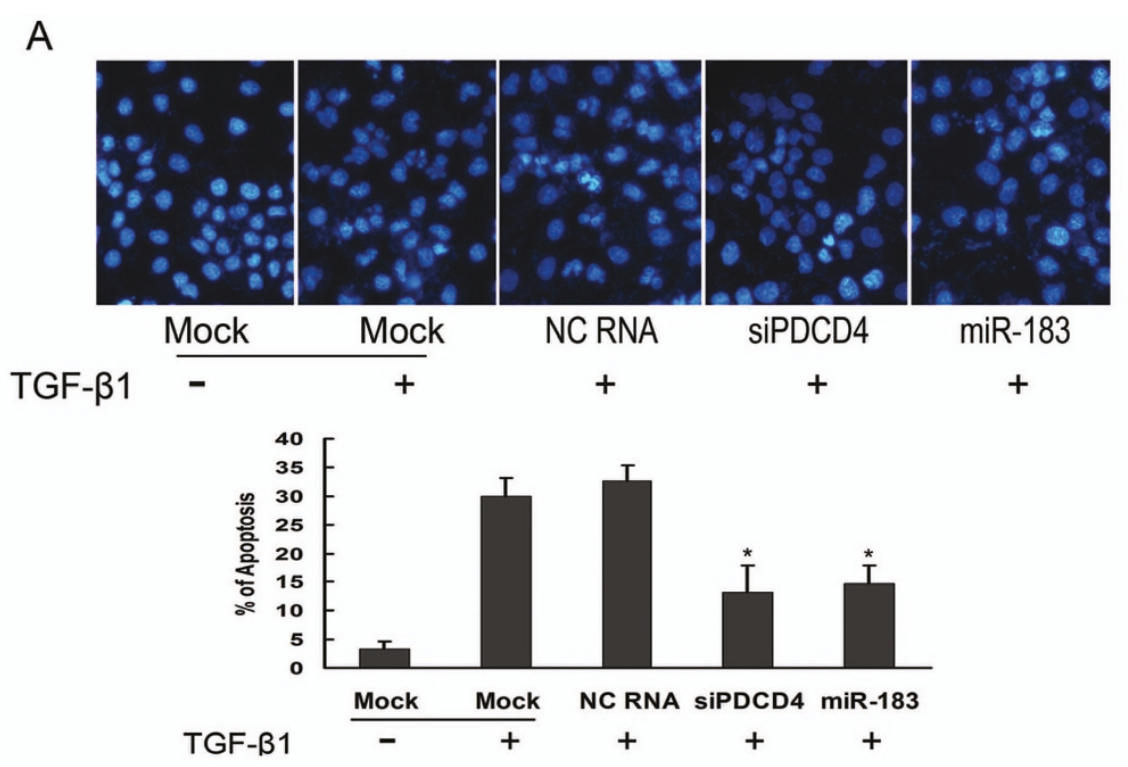

B
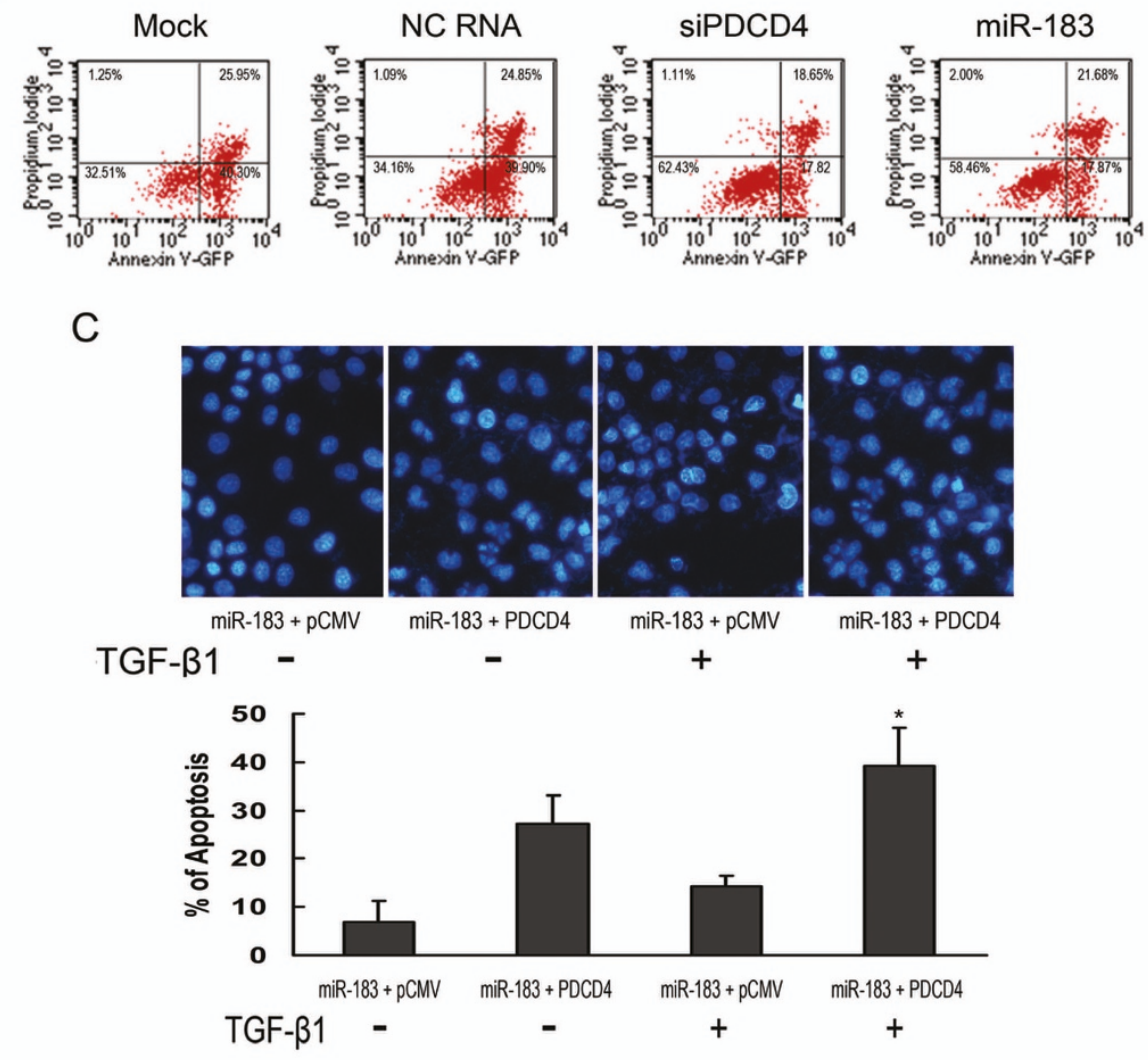

Figure 4 miR-183 transfectants were resistant to apoptosis induced by TGF- $\beta 1$. (A) DAPI assay. Huh7 cells were transfected with NC RNA, siPDCD4, or miR-183 respectively, after 24 hours, TGF- $\beta 1$ ( $5 \mathrm{ng} / \mathrm{mL})$ was added. Cells were further incubated for 48 hours, fixed, and stained with DAPI. ${ }^{*} P<0.05$ compared with Huh7 cells transfected with NC RNA. (B) Annexin-V assays. Huh7 cells were transfected and cultured as described in (A), then collected by trypsinization followed by centrifugation and stained with FITC conjugated Annexin-V and PI. (C) miR-183 and PDCD4 expression vector were cotransfected into Huh7 cells, after 24 hours, TGF- $\beta 1(5 \mathrm{ng} / \mathrm{mL})$ was added. Cells were further incubated for 48 hours, fixed, and stained with DAPI. * $\mathrm{P}<0.05$ compared with Huh7 cells transfected with control pCMV vector. 
target of miR-21 in various aspects of tumor progression: cell proliferation, invasion, metastasis, and neoplastic transformation in breast cancer [27,29,30], invasion, intravasation, and metastasis in colon cancer [28], proliferation and invasion in esophageal squamous cell carcinoma [31]. Here, we found that PDCD4 was negatively regulated by miR-183 in HCC cells. All these data suggest the regulation mechanism of PDCD4 is very complex, many factors (either protein or RNA) might influence the expression of PDCD4.

\section{Conclusions}

This study suggests that miR-183, up-regulated in HCC, represses the expression of the tumor-suppressor PDCD4 posttranscriptionally, and inhibits TGF- $\beta 1$-induced apoptosis in human HCC cells. Therefore, miR-183 may play an important role in HCC development.

\section{Abbreviations}

miRNA: microRNA; PDCD4: Programmed cell death protein 4; UTR: untranslated region; qRT-PCR: quantitative real-time PCR.

\section{Competing interests}

The authors declare that they have no competing interests.

\section{Authors' contributions}

$J L, H F, C X, Y T, R X$ and JZ performed experiments; $H F$ and $X Z$ designed research and wrote the paper; $\mathrm{HF}, \mathrm{YQ}, \mathrm{ZS}$ and $\mathrm{XZ}$ analyzed data. All authors read and approved the final manuscript.

\section{Acknowledgements}

This work was supported partially by Chinese State Key Projects for Basic Research (2010CB912801, 2009CB521804, 2007CB914601, 2006CB910407), Chinese National Natural Science Foundation project (30873008, 30870529)

\section{Author Details}

'Beijing Institute of Radiation Medicine, 27 Taiping Road, Beijing 100850, People's Republic of China and 'Department of Biochemistry and Molecular Biology, Anhui Medical University, 81 Meishan Road, Hefei 230032, People's Republic of China

Received: 26 October 2009 Accepted: 6 July 2010 Published: 6 July 2010

\section{References}

1. El-Serag HB, Rudolph KL: Hepatocellular carcinoma: epidemiology and molecular carcinogenesis. Gastroenterology 2007, 132(7):2557-2576.

2. Jemal A, Siegel R, Ward E, Hao Y, Xu J, Murray T, Thun MJ: Cancer statistics, 2008. CA Cancer J Clin 2008, 58(2):71-96.

3. Pisani P, Parkin DM, Bray F, Ferlay J: Erratum: Estimates of the worldwide mortality from 25 cancers in 1990. Int. J. Cancer, 83, 18-29 (1999). Int J Cancer 1999, 83(6):870-873.

4. Villanueva A, Newell P, Chiang DY, Friedman SL, Llovet JM: Genomics and signaling pathways in hepatocellular carcinoma. Semin Liver Dis 2007, 27(1):55-76.

5. Kutay H, Bai S, Datta J, Motiwala T, Pogribny I, Frankel W, Jacob ST, Ghoshal $\mathrm{K}$ : Downregulation of miR-122 in the rodent and human hepatocellular carcinomas. J Cell Biochem 2006, 99(3):671-678.

6. Meng F, Henson R, Wehbe-Janek H, Ghoshal K, Jacob ST, Patel T: MicroRNA-21 regulates expression of the PTEN tumor suppressor gene in human hepatocellular cancer. Gastroenterology 2007, 133(2):647-658.

7. Wong QW, Lung RW, Law PT, Lai PB, Chan KY, To KF, Wong N: MicroRNA223 is commonly repressed in hepatocellular carcinoma and potentiates expression of Stathmin1. Gastroenterology 2008, 135(1):257-269.
8. Varnholt H, Drebber U, Schulze F, Wedemeyer I, Schirmacher P, Dienes HP, Odenthal M: MicroRNA gene expression profile of hepatitis $C$ virusassociated hepatocellular carcinoma. Hepatology 2008, 47(4):1223-1232.

9. Pillai RS, Bhattacharyya SN, Artus CG, Zoller T, Cougot N, Basyuk E, Bertrand E, Filipowicz W: Inhibition of translational initiation by Let-7 MicroRNA in human cells. Science 2005, 309(5740):1573-1576.

10. Zamore PD, Haley B: Ribo-gnome: the big world of small RNAs. Science 2005, 309(5740):1519-1524.

11. Johnson SM, Grosshans H, Shingara J, Byrom M, Jarvis R, Cheng A, Labourier E, Reinert KL, Brown D, Slack FJ: RAS is regulated by the let-7 microRNA family. Cell 2005, 120(5):635-647.

12. Calin GA, Dumitru CD, Shimizu M, Bichi R, Zupo S, Noch E, Aldler H, Rattan S, Keating M, Rai K, et al.: Frequent deletions and down-regulation of micro-RNA genes miR15 and miR16 at 13q14 in chronic lymphocytic leukemia. Proc Natl Acad Sci USA 2002, 99(24):15524-15529.

13. Cimmino A, Calin GA, Fabbri M, lorio MV, Ferracin M, Shimizu M, Wojcik SE, Aqeilan Rl, Zupo S, Dono M, et al:: miR-15 and miR-16 induce apoptosis by targeting BCL2. Proc Natl Acad Sci USA 2005, 102(39):13944-13949.

14. O'Donnell KA, Wentzel EA, Zeller KI, Dang CV, Mendell JT: c-Mycregulated microRNAs modulate E2F1 expression. Nature 2005, 435(7043):839-843.

15. Gramantieri L, Ferracin M, Fornari F, Veronese A, Sabbioni S, Liu CG, Calin GA, Giovannini C, Ferrazzi E, Grazi GL, et al: Cyclin G1 is a target of miR122a, a microRNA frequently down-regulated in human hepatocellular carcinoma. Cancer Res 2007, 67(13):6092-6099.

16. Liu Q, Fu H, Sun F, Zhang H, Tie Y, Zhu J, Xing R, Sun Z, Zheng X: miR-16 family induces cell cycle arrest by regulating multiple cell cycle genes. Nucleic Acids Res 2008, 36(16):5391-5404

17. Bitomsky N, Wethkamp N, Marikkannu R, Klempnauer KH: siRNAmediated knockdown of Pdcd4 expression causes upregulation of p21(Waf1/Cip1) expression. Oncogene 2008, 27(35):4820-4829.

18. Lewis BP, Burge CB, Bartel DP: Conserved seed pairing, often flanked by adenosines, indicates that thousands of human genes are microRNA targets. Cell 2005, 120(1):15-20.

19. Zhang H, Ozaki I, Mizuta T, Hamajima H, Yasutake T, Eguchi $Y$, Ideguchi $H$, Yamamoto K, Matsuhashi S: Involvement of programmed cell death 4 in transforming growth factor-beta1-induced apoptosis in human hepatocellular carcinoma. Oncogene 2006, 25(45):6101-6112.

20. Bastian BC, LeBoit PE, Hamm H, Brocker EB, Pinkel D: Chromosomal gains and losses in primary cutaneous melanomas detected by comparative genomic hybridization. Cancer Res 1998, 58(10):2170-2175.

21. Motoyama K, Inoue H, Takatsuno Y, Tanaka F, Mimori K, Uetake H, Sugihara K, Mori M: Over- and under-expressed microRNAs in human colorectal cancer. Int J Oncol 2009, 34(4):1069-1075.

22. Lin WM, Baker AC, Beroukhim R, Winckler W, Feng W, Marmion JM, Laine E, Greulich $\mathrm{H}$, Tseng $\mathrm{H}$, Gates $\mathrm{C}$, et al:: Modeling genomic diversity and tumor dependency in malignant melanoma. Cancer Res 2008, 68(3):664-673.

23. Wang G, Mao W, Zheng S: MicroRNA-183 regulates Ezrin expression in lung cancer cells. FEBS Lett 2008, 582(25-26):3663-3668.

24. Soejima H, Miyoshi O, Yoshinaga H, Masaki Z, Ozaki I, Kajiwara S, Niikawa $\mathrm{N}$, Matsuhashi S, Mukai T: Assignment of the programmed cell death 4 gene (PDCD4) to human chromosome band $10 \mathrm{q} 24$ by in situ hybridization. Cytogenet Cell Genet 1999, 87(1-2):113-114.

25. Yang HS, Jansen AP, Komar AA, Zheng X, Merrick WC, Costes S, Lockett SJ, Sonenberg N, Colburn NH: The transformation suppressor Pdcd4 is a novel eukaryotic translation initiation factor $4 \mathrm{~A}$ binding protein that inhibits translation. Mol Cell Biol 2003, 23(1):26-37.

26. Jansen AP, Camalier CE, Colburn NH: Epidermal expression of the translation inhibitor programmed cell death 4 suppresses tumorigenesis. Cancer Res 2005, 65(14):6034-6041.

27. Frankel LB, Christoffersen NR, Jacobsen A, Lindow M, Krogh A, Lund AH: Programmed cell death 4 (PDCD4) is an important functional target of the microRNA miR-21 in breast cancer cells. J Biol Chem 2008 , 283(2):1026-1033.

28. Asangani IA, Rasheed SA, Nikolova DA, Leupold JH, Colburn NH, Post S Allgayer H: MicroRNA-21 (miR-21) post-transcriptionally downregulates tumor suppressor Pdcd4 and stimulates invasion, intravasation and metastasis in colorectal cancer. Oncogene 2008, 27(15):2128-2136. 
29. Zhu S, Wu H, Wu F, Nie D, Sheng S, Mo YY: MicroRNA-21 targets tumor suppressor genes in invasion and metastasis. Cell Res 2008, 18(3):350-359

30. Lu Z, Liu M, Stribinskis V, Klinge CM, Ramos KS, Colburn NH, Li Y: MicroRNA-21 promotes cell transformation by targeting the programmed cell death 4 gene. Oncogene 2008, 27(31):4373-4379.

31. Hiyoshi Y, Kamohara H, Karashima R, Sato N, Imamura Y, Nagai Y, Yoshida $N$, Toyama E, Hayashi N, Watanabe M, et al:: MicroRNA-21 regulates the proliferation and invasion in esophageal squamous cell carcinoma. Clin Cancer Res 2009, 15(6):1915-1922.

\section{Pre-publication history}

The pre-publication history for this paper can be accessed here: http://www.biomedcentral.com/1471-2407/10/354/prepub

doi: $10.1186 / 1471-2407-10-354$

Cite this article as: Li et al., miR-183 inhibits TGF-?1-induced apoptosis by downregulation of PDCD4 expression in human hepatocellular carcinoma cells BMC Cancer 2010, 10:354

Submit your next manuscript to BioMed Central and take full advantage of:

- Convenient online submission

- Thorough peer review

- No space constraints or color figure charges

- Immediate publication on acceptance

- Inclusion in PubMed, CAS, Scopus and Google Scholar

- Research which is freely available for redistribution

Submit your manuscript at www.biomedcentral.com/submit 